Fixed Point Theory, 21(2020), No. 1, 239-258

DOI: $10.24193 /$ fpt-ro.2020.1.17

http://www.math.ubbcluj.ro/ nodeacj/sfptcj.html

\title{
POSITIVE PIECEWISE PSEUDO ALMOST PERIODIC SOLUTIONS OF A GENERALIZED HEMATOPOIESIS MODEL WITH HARVESTING TERMS AND IMPULSES
}

\author{
FANCHAO KONG \\ Department of Mathematics, Anhui Normal University, Wuhu 241000, Anhui, P.R.China \\ E-mail: fanchaokong88@yahoo.com
}

\begin{abstract}
This paper is mainly concerned with a generalized hematopoiesis model with harvesting terms and impulses. Based on the contraction mapping principle and generalized Gronwall-Bellmain inequality, the new results on the existence, uniqueness and globally exponential stability of the positive piecewise pseudo almost periodic solutions of the addressed model are established. Some corresponding results in the literature can be complemented and extended. In addition, an example is given to illustrate the effectiveness of the new obtained results.

Key Words and Phrases: Positive piecewise pseudo almost periodic solution, hematopoiesis model, harvesting term, impulses, contraction mapping principle, generalized Gronwall-Bellmain inequality.
\end{abstract}

2010 Mathematics Subject Classification: 34C27, 92H10, 47H10.

\section{Conclusion}

In this paper, we investigate generalized hematopoiesis model with harvesting terms and impulses, which are more generalized and different from the corresponding ones known in the literature. The results on the existence and uniqueness of positive piecewise pseudo almost periodic solution have been completely established by means of the contraction mapping principle, the global exponential stability of pseudo almost periodic solutions are further obtained by applying the generalized Gronwall-Bellmain inequality. Our results can improve and extend previous works in the literature.

Acknowledgments. The authors thank the anonymous reviewers for their insightful suggestions which improved this work significantly.

\section{REFERENCES}

[1] A.I. Alonso, J. Hong, J. Rojo, A class of ergodic solutions of differential equations with piecewise constant arguments, Dynam. Syst. Appl., 7(1998), 561-574.

[2] J.O. Alzabut, J.J. Nieto, G.T. Stamov, Existence and exponential stability of positive almost periodic solutions for a model of hematopoiesis, Bound. Value Probl., 2009(2009), 1-10.

[3] J.O. Alzabut, G.T. Stamov, E. Sermutlu, On almost periodic solutions for an impulsive delay logarithmic population model, Math. Comput. Model., 51(2010), 625-631. 
[4] C. Aouiti, M.S. M'hamdi, J.D. Cao, Piecewise pseudo almost periodic solution for impulsive generalized high-order hopfield neural networks with leakage delays, Neural Processing Letters, 45(2017), no. 2, 615-648.

[5] L. Bai, J.J. Nieto, Variational approach to differential equations with not instantaneous impulses, Appl. Math. Letters, 73(2017), 44-48.

[6] F. Chérif, Pseudo almost periodic solution of Nicholson's blowflies model with mixed delays, Appl. Math. Model., 39(2015), 5152-5163.

[7] H.S. Ding, Q.L. Liu, J.J. Nieto, Existence of positive almost periodic solutions to a class of hematopoiesis model, Appl. Math. Model., 40(2016), 3289-3297.

[8] H.S. Ding, G.M. N'Guérékata, J.J. Nieto, Weighted pseudo almost periodic solutions for a class of discrete hematopoiesis model, Rev. Mat. Comput., 26(2013), 427-443.

[9] H.S. Ding, J.J. Nieto, A new approach for positive almost periodic solutions to a class of Nicholson's blowflies model, J. Comput. Appl. Math., 253(2013), 249-254.

[10] I. Györi, G. Ladas, Oscillation Theory of Delay Differential Equations with Applications, Clarendon, 1991.

[11] J.K. Hale, Theory of Functional Differential Equations, Springer, New York, 1977.

[12] F.C. Kong, Positive piecewise pseudo-almost periodic solutions of first-order singular differential equations with impulses, J. Fixed Point Theory Appl., 19(2017), 2397-2416.

[13] F.C. Kong, Z.G. Luo, Positive periodic solutions for a kind of first-order singular differential equation induced by impulses, Qual. Theory Dyn. Syst., 17(2018), 375-386.

[14] J.W. Liu, C.Y. Zhang, Composition of piecewise pseudo almost periodic functions and applications to abstract impulsive differential equations, Adv. Differ. Equ., 11(2013), 1-21.

[15] M.C. Mackey, L. Glass, Oscillations and chaos in physiological control system, Sciences, 197(1977), 287-289.

[16] J.X. Meng, Global exponential stability of positive pseudo-almost-periodic solutions for a model of hematopoiesis, Abstr. Appl. Anal., 2013(2013), 1-7.

[17] L.F. Nie, Z.D. Teng, J.J. Nieto, I.H. Jung, State impulsive control strategies for a two-languages competitive model with bilingualism and interlinguistic similarity, Phys. A., 430(2015), 136-147.

[18] S.H. Saker, Oscillation and global attractivity in hematopoiesis model with periodic coefficients, Appl. Math. Comput., 142(2003), no. 2-3, 477-494.

[19] A.M. Samoilenko, N.A. Perestyuk, Impulsive Differential Equations, Vol. 14, World Scientific, Singapore, 1995.

[20] G.T. Stamov, Almost Periodic Solutions of Impulsive Differential Equations, Springer-Verlag, Berlin, 2012.

[21] I. Stamova, G. Stamov, Applied Impulsive Mathematical Models, CMS Books in Mathematics/Ouvrages de Mathmatiques de la SMC. Springer, 2016.

[22] I.M. Stamova, G.T. Stamov, Functional and Impulsive Differential Equations of Fractional Order, Qualitative Analysis and Applications, CRC Press, Boca Raton, FL, 2017.

[23] J.T. Sun, J.F. Chu, H.B. Chen, Periodic solution generated by impulses for singular differential equations, J. Math. Anal. Appl., 404(2013), 562-569.

[24] X. Wang, Z.X. Li, Dynamics for a class of general hematopoiesis model with periodic coefficients, Appl. Math. Comput., 186(2007), 460-468.

[25] P.X. Weng, Global attractivity of periodic solution in a model of hematopoiesis, Comput. Math. Appl., 44(8-9)(2002), 1019-1030.

[26] X.M. Wu, J.W. Li, H.Q. Zhou, A necessary and sufficient condition for the existence of positive periodic solutions of a model of hematopoiesis, Comput. Math. Appl., 54(6)(2007), 840-849.

[27] Z.J. Yao, New results on existence and exponential stability of the unique positive almost periodic solution for hematopoiesis model, Appl. Math. Model., 39(2015), 7113-7123.

[28] S.T. Zavalishchin, A.N. Sesekin, Dynamic Impulse Systems, Theory and Applications, Mathematics and its Applications, 394 Kluwer Academic Publishers Group, Dordrecht, 1997.

[29] C.Y. Zhang, Pseudo almost periodic solutions of some differential equations, J. Math. Anal. Appl., 151(1994), 62-76.

[30] C.Y. Zhang, Pseudo almost periodic solutions of some differential equations II, J. Math. Anal. Appl., 192(1995), 543-561. 
[31] C.Y. Zhang, Almost Periodic Type Functions and Ergodicity, Kluwer Academic/ Science Press, Beijing, 2003.

[32] H. Zhang, M.Q. Yang, L.J. Wang, Existence and exponential convergence of the positive almost periodic solution for a model of hematopoiesis, Appl. Math. Letters, 26(2013), 38-42.

Received: September 21, 2017; Accepted: February 1, 2018. 